\title{
LA-UR-17-27631
}

Approved for public release; distribution is unlimited.

Title: $\quad$ Opportunities at the International Atomic Energy Agency (IAEA)

Author(s): $\quad$ Rosenberg, Nina Dale

Intended for: $\quad$ Presentation at the 2017 Postdoc Research Symposium \& Career Fair.

Issued: 2017-08-24 
Disclaimer:

Los Alamos National Laboratory, an affirmative action/equal opportunity employer, is operated by the Los Alamos National Security, LLC for the National Nuclear Security Administration of the U.S. Department of Energy under contract DE-AC52-06NA25396. By approving this article, the publisher recognizes that the U.S. Government retains nonexclusive, royalty-free license to publish or reproduce the published form of this contribution, or to allow others to do so, for U.S. Government purposes. Los Alamos National Laboratory requests that the publisher identify this article as work performed under the auspices of the U.S. Department of Energy. Los Alamos National Laboratory strongly supports academic freedom and a researcher's right to publish; as an institution, however, the Laboratory does not endorse the viewpoint of a publication or guarantee its technical correctness. 


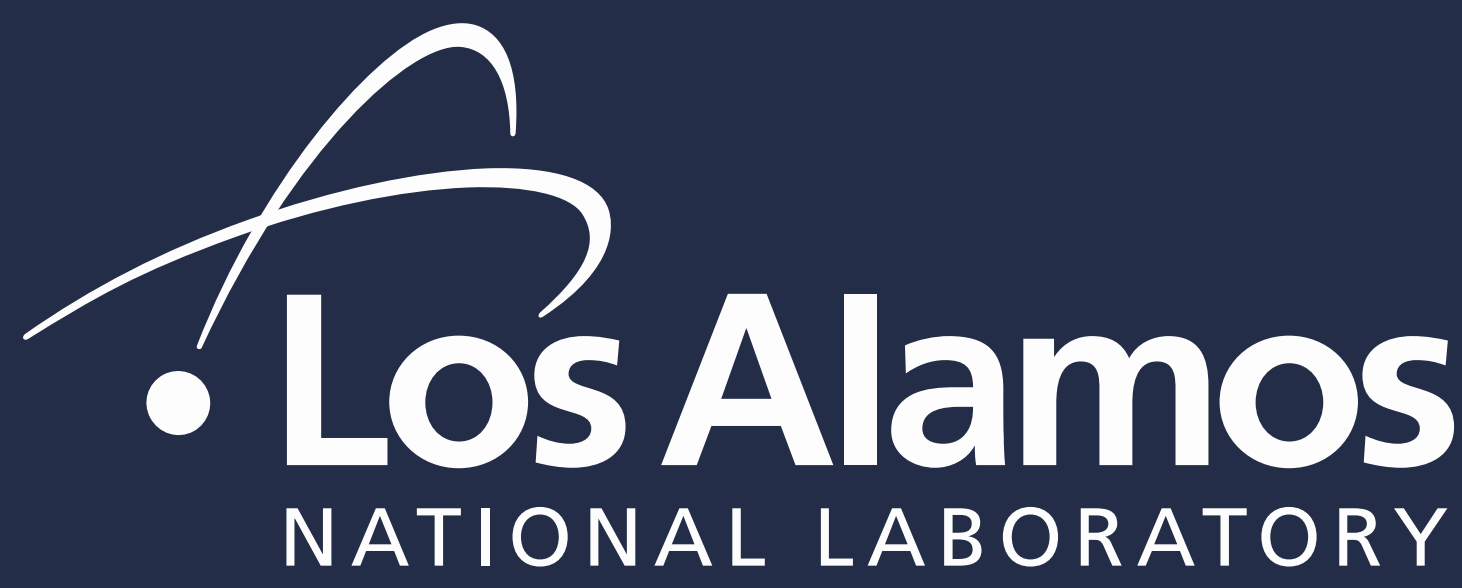

EST.1943

\section{Opportunities at the International Atomic Energy Agency (IAEA)} Presentation at the 2017 Postdoc Research Symposium \& Career Fair

Nina D. Rosenberg

Program Director, Nuclear Nonproliferation and Security 
The IAEA is the world's most important forum for S\&T cooperation in the peaceful use of nuclear technology

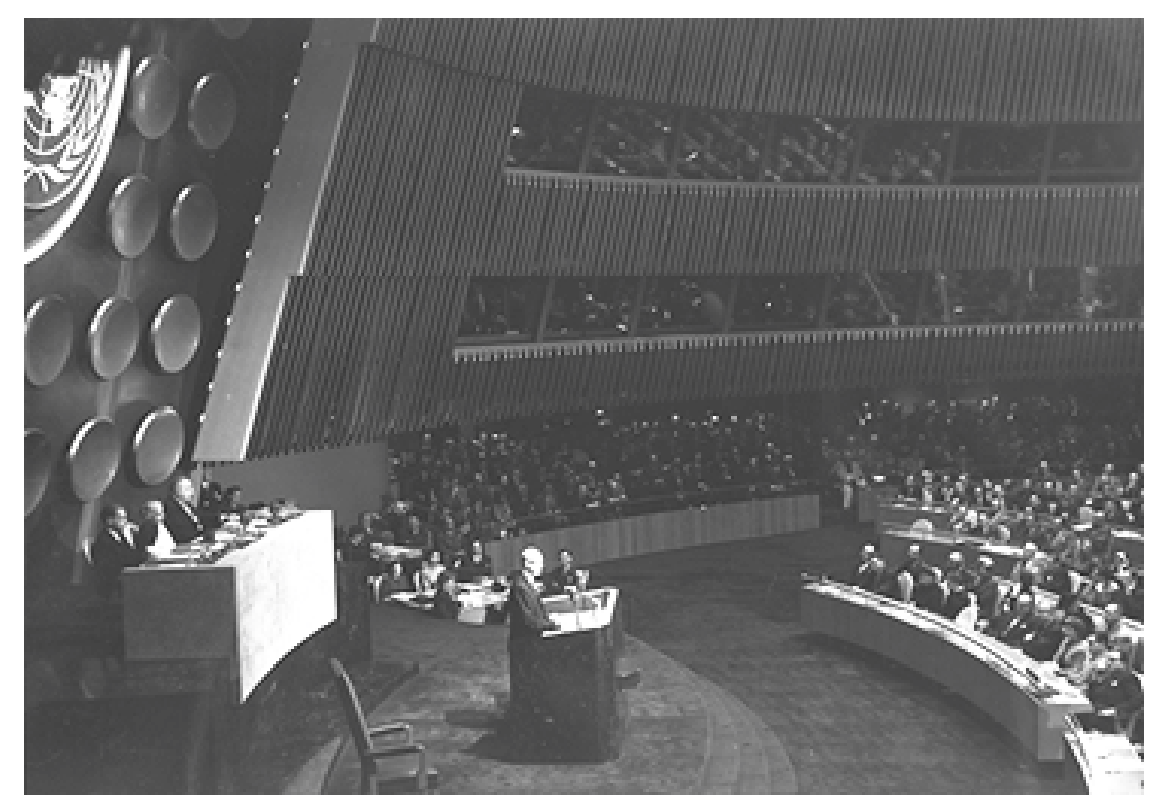

Established in 1957, following President Eisenhower's "Atoms for Peace" speech at the United Nations

International treaty organization comprising 168 Member States

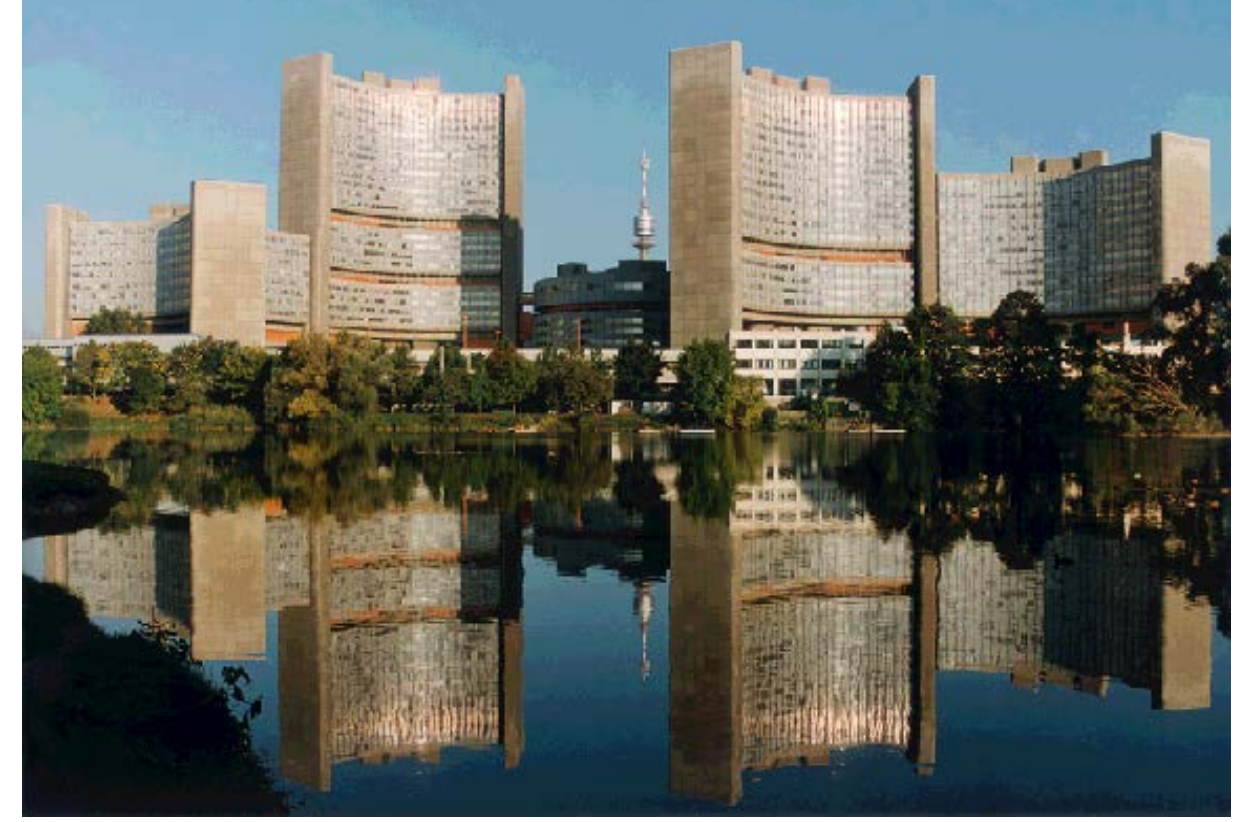


The IAEA is headquartered in Vienna, Austria

- 2500 staff from $>90$ countries

- Regional offices in Toronto; Tokyo

- Liaison offices in New York; Geneva

- Research laboratories in Seibersdorf, Austria; Monaco
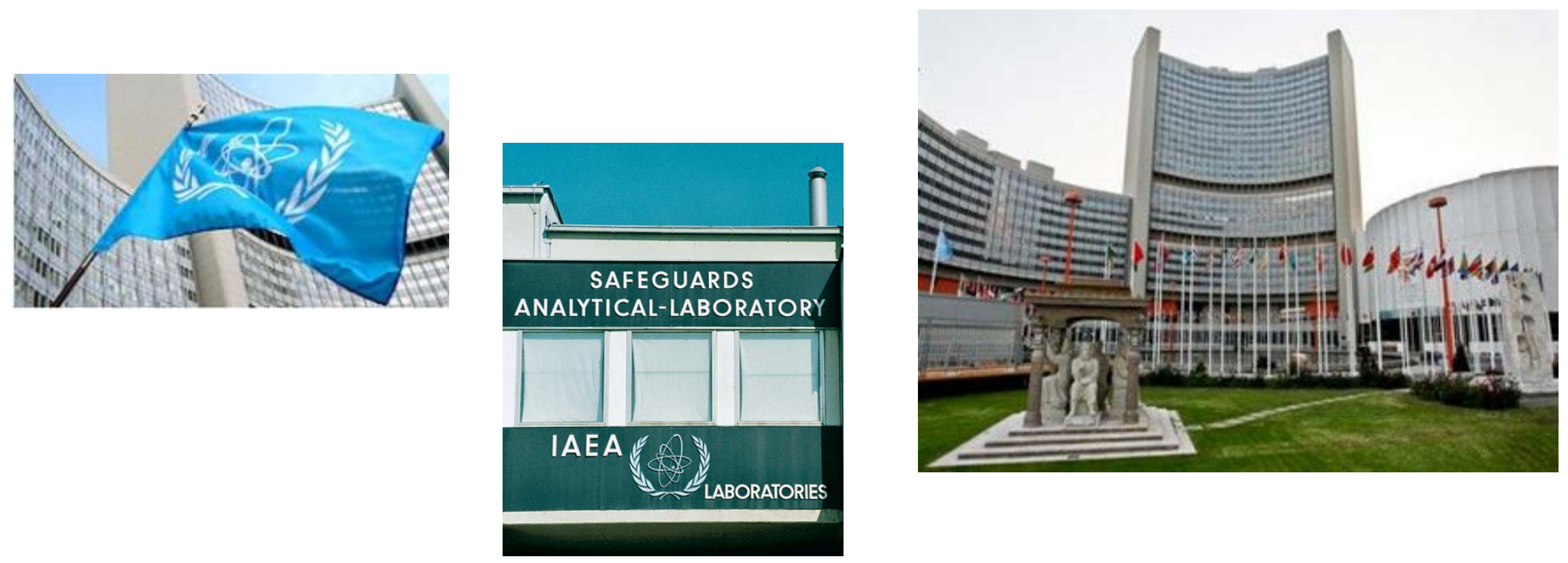


\section{The IAEA's work is build upon three pillars:}

\section{Science and Technology}

Advise and provide training/services to Member States on nuclear energy, and nuclear/isotope techniques in water resources, human health, agriculture, etc.

\section{Safety and Security}

Assist Member States build capabilities and work to strengthen nuclear safety and security framework globally

\section{Safeguards and Verification}

Implement safeguards to verify that nuclear material in Member States is used only for peaceful purposes by verifying correctness and completeness of nuclear declarations 


\section{IAEA Organization}

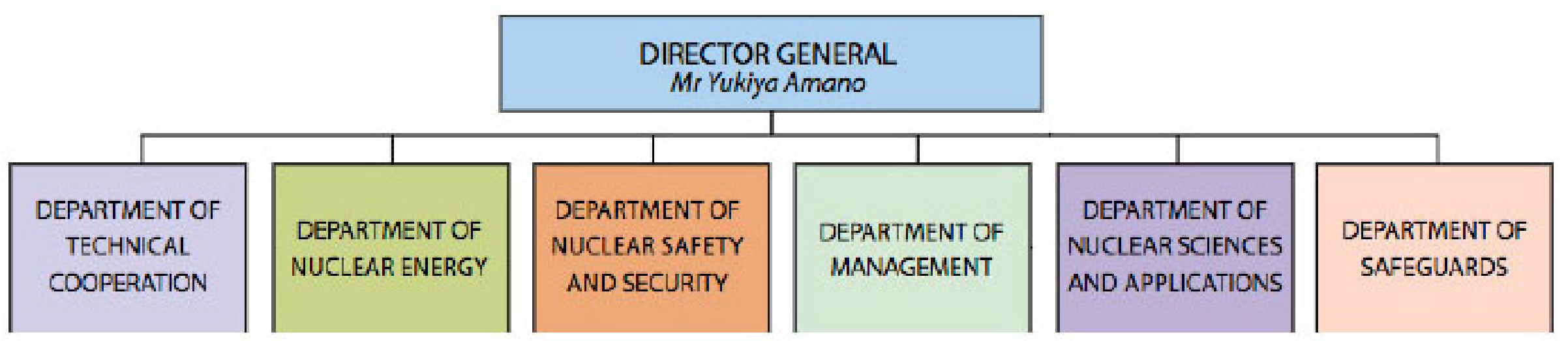




\section{IAEA professional staff}

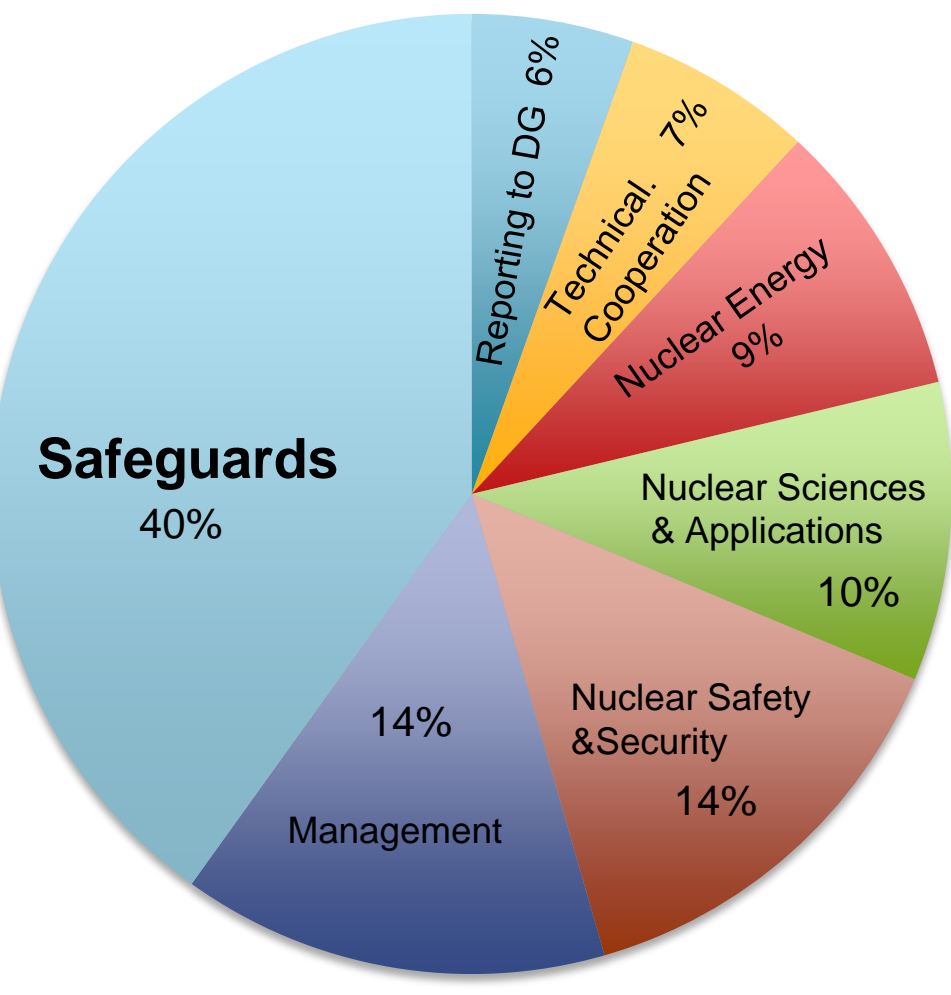

U.S.

$14 \%$

Non-U.S. 86\%




Los Alamos has been providing end-to-end support for 50 years to meet the IAEA's evolving safeguards needs

Los Alamos has pioneered a wide range of IAEA measurement tools in use today and continues to innovate with new technology

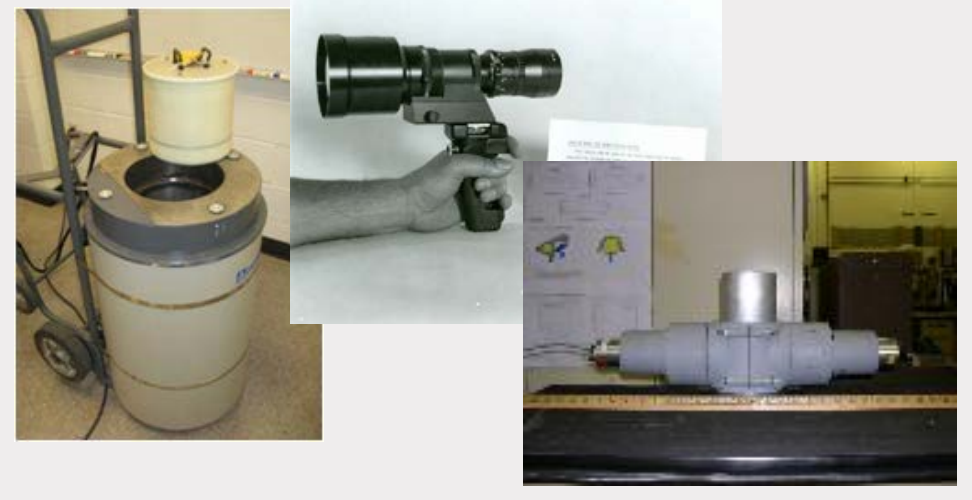

Every new IAEA inspector since 1980 comes to Los Alamos for training

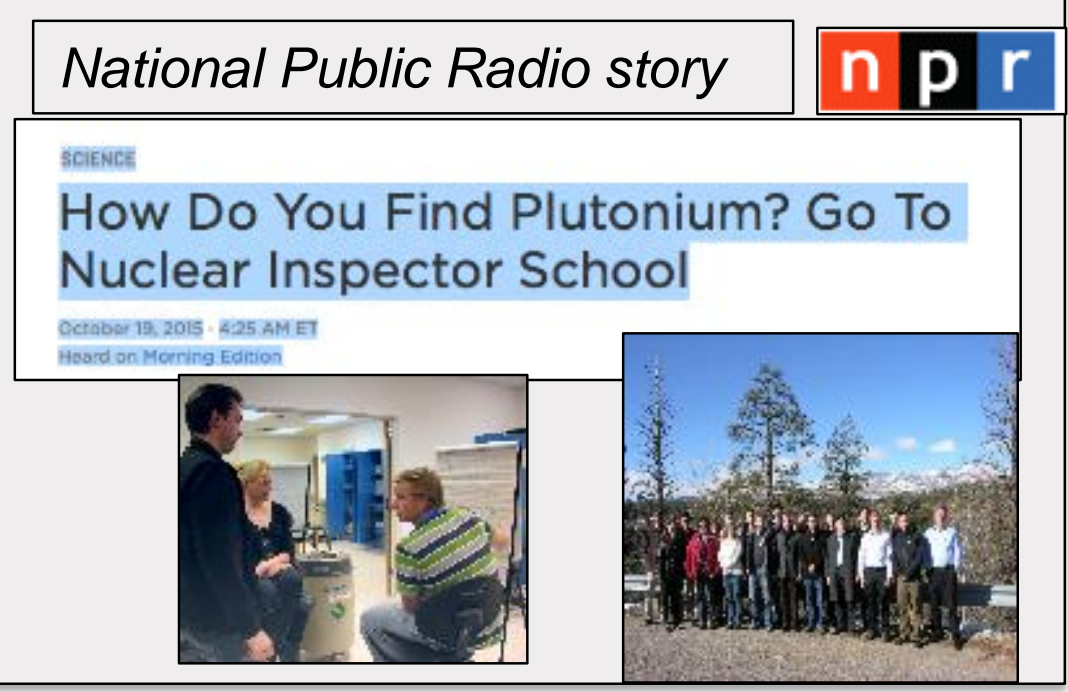

Los Alamos encourages staff to take temporary assignments at the IAEA, primarily in the Safeguards Department

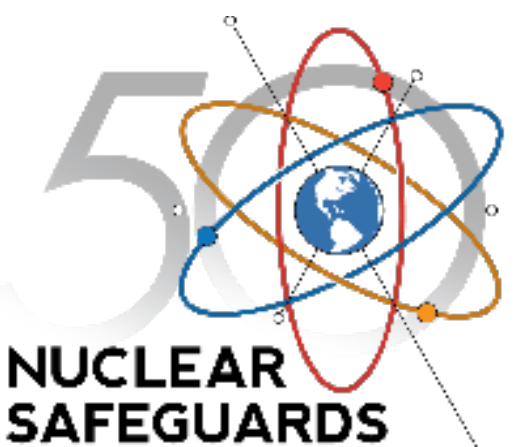

SAFEGUARDS

LOS ALAMOS NATIONAL LABORATORY 


\section{IAEA Employment Opportunities - Staff Positions}

- No permanent appointments; jobs are typically 3-7 years

- Positions are categorized as P1 - P5, depending on education, experience

- Benefits are excellent, including school tuition assistance

- IAEA posts vacancy announcements on its website

- Candidate completes online profile and submits it to the IAEA

- IAEA electronically reviews the application

- Selected applications interview online, via video conference

- Process takes at least 6 months, and is often longer 
- Opportunity to work at the IAEA in Vienna for up to 2 years

- Applicants must be U.S. citizens, 18-32 years old

- Requires an advanced university degree in relevant technical field

- Positions are funded by U.S. outside of regular IAEA budget

- Benefits mainly comparable to regular IAEA staff

- IAEA submits requests for safeguards positions to the International Safeguards Project Office (Brookhaven) and for non-safeguards positions to the IAEA Program Office (Argonne)

- Candidates submit application materials through one of these U.S. offices which serve as the interface to the IAEA for these positions

- Process can take at least 8 months, and is often longer 


\section{IAEA Employment Opportunities - Cost-Free Experts (CFE)}

- CFEs have specialized skills not readily available among the IAEA professional staff

- Positions are funded by U.S. outside of regular IAEA budget

- Benefits mainly comparable to regular IAEA staff

- IAEA submits requests for safeguards positions to the International Safeguards Project Office (Brookhaven) and for non-safeguards positions to the IAEA Program Office (Argonne)

- Candidates submit application materials through one of these U.S. offices which serve as the interface to the IAEA for these positions

- Process can take at least 8 months, and is often longer 


\section{Information and tips for applying for IAEA positions can be found on IAEA and National Lab websites}

\section{Tips for Applying}

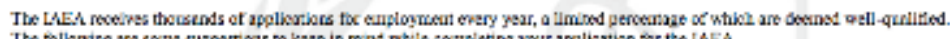

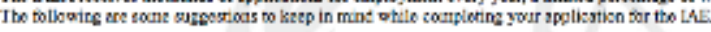

1) APPLY SELECTNELY

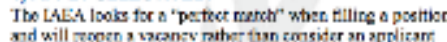

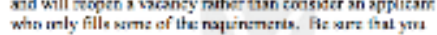

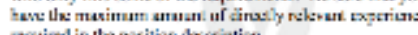

2) TAILOR YOUR APPLICATION TO THE JOB

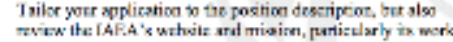

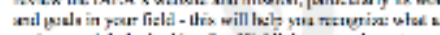

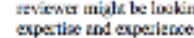

3) PROVIDE DETALED DESCRIPTIONS

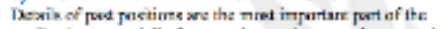

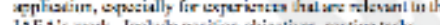

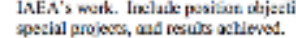

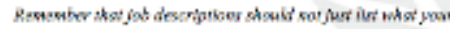

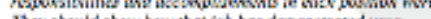
2ay

gusilibanion:



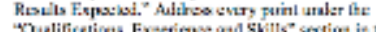

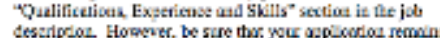

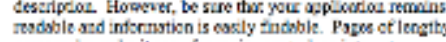

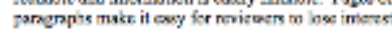



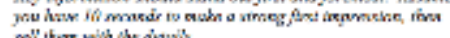

4) UTLLZE KEY WOADS

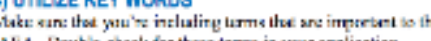
IALA. Dosibiocteck for these temre in your apslization

5) NOTE MANAGERIAL EXPERIENCE

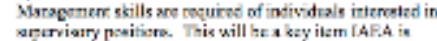

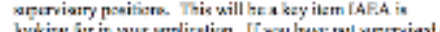

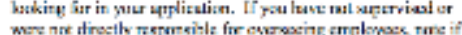

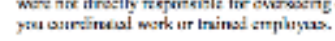

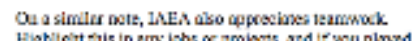

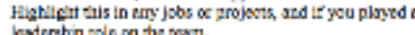

6) NOTE LAEA \& INTERNATIONAL ACTNITIES

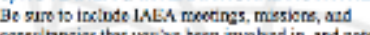

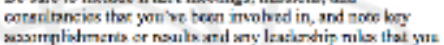

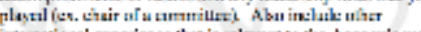

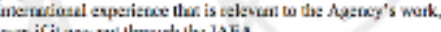

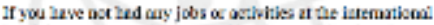

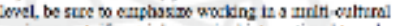

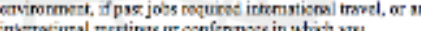

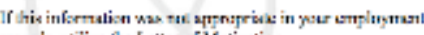

7) INCLUDE LANGUAGE SKILLS

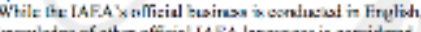
krow botge of
satsantiganas.

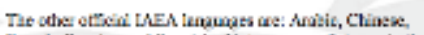


or other inguspee.

8) FULYY UTILIZE THE LETTER OF MOTIVATION



9) DOUBLE.CHECK FOR TYPOS

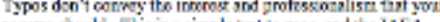

10) CHOOSE REFERENCES CAREFULLY

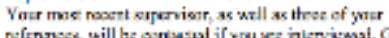

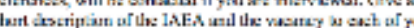

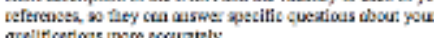

11) UPDATE YOUR APPUCATION

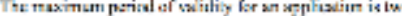

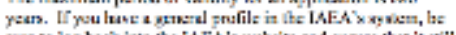

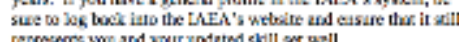

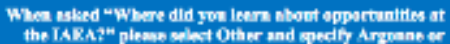

\section{9 people clipped this ellide}

\section{Preparing for a job interview}

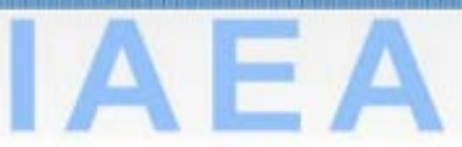

A webinar

by

Jack Preston (Recruitment Officer, LEEA)

(8) human 


\section{Resources}

- For information about IAEA vacancies and benefits, see www.iaea.org/about/employment

- ISPO website: www.bnl.gov/ispo/

Based at Brookhaven, the International Safeguards Project Office (ISPO) is responsible for the technical and administrative management of the U.S.

Support Program to the International Atomic Energy Agency (IAEA) Safeguards Division

- IAEA Program Office website: international.anl.gov

Based at Argonne, this office manages the U.S. interface to the nonSafeguards IAEA support program

- Talk with Los Alamos staff who have worked at the IAEA or currently engage in work with the IAEA 


\section{Living in Vienna}

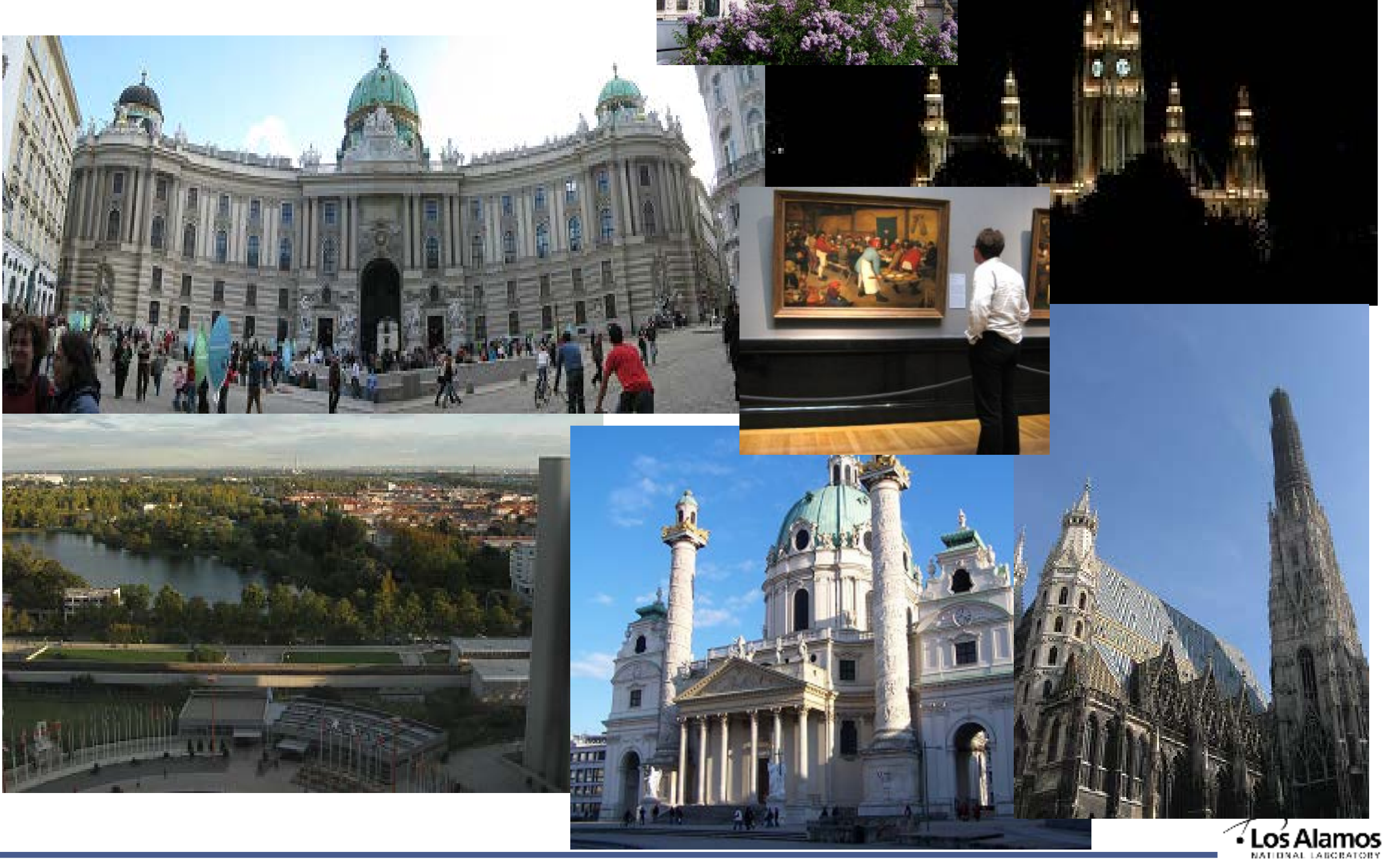

